\title{
PERANCANGAN ENTERPRISE ARCHITECTURE PLANNING \\ DENGAN ZACHMAN FRAME WORK (STUDI KASUS : CV.RIA KENCANA UNGU)
}

\author{
Deby Tri Sundari ${ }^{1}$, Novri Hadinata ${ }^{22}$ \\ Fakultas Ilmu Komputer, Universitas Bina Darma \\ Email: deby.ts97@gmail.com¹, novri_hadinata@binadarma.ac.id ${ }^{2}$
}

\begin{abstract}
The importance of an integrated data within the company is called an enterprise. The existence of well- organized data in one managed data source is the goal of company development to make this happen, strategy and planning are needed. It is known that Cv. Ria Kencana Ungu requires management in the development of information technology. One problem faced by RKU Computer is the application of business process design, most of which have not used the system and are still manually recording to copy transaction process data as well as reporting data services so that the data processing is not yet used. effective and not sustainable. The implementation of enterprise architecture planning with the zachman framework results achieved in the implementation of enterprise architecture planning to produce a blueprint that can serve as a guideline that can illustrate designing architecture in Cv. Ria Kencana Ungu is proven to be very important for an enterprise. With the proposed application candidates can improve information systems based on current business processes so that the need for information technology that supports business needs can be a reference in long-term technology investment in Cv. Ria Kencana Ungu.
\end{abstract}

Keywords: Enterprise atchitecture planning, Information Technology, zachman framework, blueprint

\begin{abstract}
Abstrak
Pentingnya sebuah data yang terintegrasi didalam perusahaan disebut enterprise adanya data yang tesusun baik dalam satu sumber data yang dikelola merupakan tujuan pengembangan perusahaan untuk mewujudkan hal tersebut diperlukan strategi dan perencanaan. Diketahui bahwa $\mathrm{Cv}$. Ria Kencana Ungu memerlukan pengelolaan dalam pengembangan teknologi informasi satu masalah yang dihadapi pada RKU Computer yaitu penerapan perancangan proses bisnis sebagian besar di setiap bagian belum menggunakan sistem dan masih melakukan pencatatan secara manual untuk menyalin data proses transaksi juga pelaporan data service sehingga menjadikan proses pengolahan data belum efektif dan tidak berkesinambungan. Penerapan rancangan enterprise architecture planning dengan zachman framework hasil yang dicapai dalam pelaksanaan enterprise architecture planning menghasilkan sebuah cetak biru yang dapat dijadikan sebagai pedoman yang dapat menggambarkan dengan merancang architecture di Cv.Ria Kencana Ungu terbukti menjadi hal yang sangat penting bagi sebuah enterprise. Dengan kandidat aplikasi yang di usulkan dapat memperbaiki sistem informasi berdasarkan proses bisnis yang sedang berjalan saat ini sehingga kebutuhan teknologi informasi yang mendukung kebutuhan bisnis yang bisa menjadi acuan dalam investasi teknologi jangka panjang di Cv. Ria Kencana Ungu
\end{abstract}

Kata Kunci : Enterprise atchitecture planning, Teknologi informasi, Zachman framework, Cetak biru

\section{Pendahuluan}

Salah satu masalah yang dihadapi pada Cv.Ria Kenacana Ungu yaitu adalah penerapan perancangan proses bisnis terutama dalam pengembangan sistem informasi pada organisasi sebagian besar di setiap bagian belum menggunakan sistem dan masih melakukan pencatatan secara manual untuk menyalin data proses transaksi penjualan dan juga pelaporan data service sehingga hal ini menjadikan proses pengolahan data belum efektif dan tidak berkesinambungan untuk menghadapi permasalahan tersebut pada $\mathrm{Cv}$. Ria Kenaca Ungu maka dalam pengembangan sistem informasi perusahaan menerapkan perencanaan enterprise architecture planning. 
Penelitian ini penting karena memberikan rekomendasi perencanaan perancangan enterprise architecture untuk menghasilkan blueprint teknologi informasi yang selaras dengan proses bisnis sehingga membantu suatu perusahaan dalam mempercepat proses menuju sasaran yang diinginkan yang sesuai dengan kebutuhan Cv. Ria Kenaca Ungu. Adapun kegiatan yang dilakukan pada penelitian ialah observasi langsung ke Cv. Ria Kenaca Ungu, studi literatur, observasi, dan wawancara langsung. Permasalahan tersebut dapat ditangani dengan sistem informasi yang disusun berdasarkan zachman framework yang dipilih karena Enterprise Architecture planning ini dapat menggambarkan kondisi organisasi secara utuh [4].

Membahas tentang penerapan rancangan enterprise architecture planning dengan zachman framework untuk menghasilkan blueprint yang nantinya dapat diimplentasikan sebagai saran untuk kemajuan perusahaan dimasa depan. Tujuannya adalah untuk mendapatkan gambaran yang jelas untuk perusahaan dan bagaimana merancangan sebuah architecture yang baik bisa digunakan oleh organisasi untuk mencapai tujuan perusahaan.

\section{Metodologi Penelitian}

Metode penelitian yang digunakan penulis menggunakan metode yang bersifat deskriptif kualitatif bertujuan untuk mendeskripsikan keadaan yang berjalan saat ini disebuah perusahaan. Menurut penelitian deskriptif kualitatif adalah suatu penelitian yang ditujukan untuk mendeskripsikan dan menganalisis fenomena, peristiwa, aktivitas sosial, sikap, kepercayaan, persepsi, pemikiran orang secara individual maupun kelompok. Data dihimpun dengan pengamatan yang seksama, mencakup deskripsi dalam konteks yang mendetail disertai catatan-catatan hasil wawancara yang mendalam. serta untuk menggambarkan atau menganalisis suatu hasil penelitian analisis tetapi tidak untuk mengambil kesimpulan yang lebih luas [1].

\subsection{Metodologi Enterprise Architecture Planning}

Metodologi yang digunakan dalam penelitian ini enterprise architecture planning (EAP) merupakan metode yang dikembangkan untuk membangun enterprise architecture, yang berorintasi dalam kebutuhan bisnis sebagai pendukung aktivitas bisnis demi mencapai tujuan organisasi. Hasil dari metodologi enterprise architecture planning adalah berupa dokumen cetak biru (blueprint) yang berupa data, aplikasi, dan teknologi. Komponen dari metodologi EAP sendiri meliputi proses dalam zachman framework, hubungan EAP dalam zachman framework mencakup pendefinisian dua baris teratas dari kerangka kerja yaitu perspektif planner dan perspektif owner [5].

\subsection{Penguraian Zachman Framework}

Pada tahap ini meninjau keseluruhan sebuah proses dari penguraian tiap-tiap perspektif pada zachman framework yang nantinya akan diubah untuk menjadi sebuah informasi, di analisis menyesuaikan kebutuhan kedalam sel pada zachman framewok agar menjadi mudah untuk dipahami dan dapat digunakan sebagai solusi dari suatu permasalahan. Identifikasi dan didefinisikan kedalam 14 sel pada zachman framework. Beberapa perspektif tersebut, sebagai berikut :

1. Perspektif planner

a. Kolom What : mengidentifikasi dan mendifinisikan hal-hal penting mengenai data dan informasi yang dibutuhan perusahaan dalam proses bisnis berupa entitas yang ada dalam lingkungan RKU Computer.

b. Kolom How: mengidentifikasi proses-proses bisnis yang ada pada RKU Computer

c. Kolom Where : mengidentifikasi lokasi yang penting dalam proses bisnis dilingkungan RKU Computer

d. Kolom Who: mengidentifikasi orang yang terlibat dalam proses bisnis

e. Kolom When : mengidentifikasi kejadian-kejadian penting terhadap proses bisnis pada RKU Computer

f. Kolom Why: mengidentifikasi tujuan startegi bisnis yang diperoleh dari rencana bisnis 
2. Perspektif owner

a. Kolom What : membuat suatu gambaran konseptual mengenai hubungan antar entitas

b. Kolom How: membuat gambaran umum tentang aktivitas organisasi dan memodelkan proses bisnis yang berjalan saat ini

c. Kolom Where : membuat suatu gambaran mengenai hubungan antar lokasi-lokasi yang terlibat dalam proses bisnsi

d. Kolom Who: menggambarkan struktur organisasi pada RKU Computer

e. Kolom When : menggambarkan jadwal dari aktifitas bisnis yang berjalan di RKU Computer f. Kolom Why: mengidentifikasi tujuan yang mendukung tujuan utama RKU Computer

3. Perspektif Designer

Model logika yang lebih rinci berisi kebutuhan dan desain batasan sistem yang di representasikan oleh para architecture sebagai designer untuk mengidentifikasi

4. Perspktif Builder

Mengintifikasi teknologi dan platform teknologi yang digunakan saat ini pada Cv.Ria Kencana Ungu

Kerangka Zachman untuk architecture perusahaan atau Zachman Framework "The Enterprise Ontology" teori keberadaan komponen sebuah perusahaan. Kerangka Kerja Zachman merupakan suatu skema dalam melakukan klasifikasi dalam pengorganisasian artifak enterprise yang dikenalkan pertama kali oleh Jhon Zachman. Zachman framework terdiri 6x6 yang dibatasi matriks di mana kolom menggambarkan dasardasar komunikasi [2] . Tiap kolom mempresentasikan fokus, abstraksi atau topik architecture enterprise, yaitu : data (atau what), fungsi (atau how), jaringan (atau where), manusia (atau who), waktu (atau when) dan motivasi (atau why). Tiap baris merepresentasikan perspektif-perspektif sebagai berikut:

a. Perspektif Perencana : menetapkan konteks, latar belakang dan tujuan enterprise.

b. Perspektif Pemilik : menetapkan model-model konseptual dari enterprise.

c. Perspektif Perancang : menetapkan model-model sistem informasi sekaligus menjembatani dan perantara hal-hal yang dapat direalisasikan secara teknis dan fisik.

d. Perspektif Pembangun : menetapkan rancangan teknis dan fisik yang digunakan dalam mengawasi implementasi teknis dan fisik.

e. Perspektif Subkontraktor : menetapkan peran dan rujukan bagi pihak bertanggung jawab untuk melakukan pembangunan secara teknis dan fisik serta mengadakan komponen-komponen yang diperlukan.

f. Perspektif Functioning enterprise: merepresentasikan perspektif pengguna dan wujud nyata hasil implementasi.

\section{Hasil Dan Pembahasan}

Menggunakan Metodologi enterprise architecture planning pada Cv.Ria Kencana Ungu dimulai dari mengumpulkan data tentang kondisi lingkungan bisnis yang berjalan saat ini pada RKU Computer. Perancangan enterprise architecture planning (EAP) pada Cv.Ria Kencana Ungu dibuat sesuai dengan kerangka penelitian sedangkan tinjauan enterprise di masa depan akan di bahas pada bab selanjutnya pada implementasi dengan kerangka kerja zachman.

\subsection{Inisialisasi Perencanaan}

Pada tahap awal dari metodologi enterprise architecture planning (EAP) yaitu inisialisasi perencanaan yang mendefinisikan Cv. Ria Kencana Ungu sebagai objek penelitian terkait dengan ruang lingkup, visi dan misi dari perencanaan sistem informasi, Yang bertujuan agar pengembangan information architecture yang dilakukan dapat sesuai dengan proses bisnis yang dijalankan oleh perusahaan. Berikut beberapa tahapan-tahapan yang dilakukan pada fase inisialisasi perencanaan : Ruang Lingkup, visi dan misi, metodologi perancangan.,Memahami Masalah, Mengumpulkan Dokumen, Rencana Tim Dan Komitmen. 


\subsection{Tinjauan Kondisi Enterprise Saat Ini}

\subsubsection{Pemodelan Bisnis}

Pemodelan bisnis mendefinisikan bisnis dari perusahaan yang menjelaskan dan menggambarkan fungsi dan proses bsnis yang dikerjakan dapat dijabarkan menjadi kegiatan-kegiatan yang dilakukan didalam perusahaan. Fungsi bisnis dapat dibagi ke dalam subfungsi yang lebih sederhana. Pada tahap ini pengembangan pemodelan bisnis yang akan dilakukan adalah sebagai berikut : Mendokumentasikan Struktur Organisasi, Peran Dan Tanggung Jawab, Fungsi Dari Proses Bisnis, Proses Bisnis

\subsubsection{Sistem Teknologi Saat Ini}

Pada tahapan sistem dan teknologi saat ini mendefinisikan sistem aplikasi dan platform teknologi yang digunakan di $\mathrm{Cv}$. Ria Kencana Ungu pada setiap bagian sesuai pekerjaan nya di RKU Computer. Inventaris sistem dan teknologi saat ini diperoleh dari hasil wawancara dengan Bapak Roy Ardi Saprianto, Shi.ST selaku pemilik RKU computer dan juga melakukan observasi langsung ke Cv. Ria Kencana Ungu memperlihatkan kondisi sistem dan teknologi saat ini.

\section{A. Analisa Kondisi Enterprise saat ini}

Berdasarkan hasil analisa kondisi saat ini di Cv. Ria Kencana Ungu baik internal maupun eksternal , Selanjutnya mengevaluasi kondisi saat ini dengan analisis SWOT menjabarkan ke dalam bentuk analisa SWOT (Strength, Weakness, Opportunity, Threat) pada Tabel 1 berisi daftar isu-isu strategis yang di formulasikan pada analisis SWOT yang merupakan analisa dari kekuatan, kelemahan faktor Internal serta kesempatan dan ancaman di lingkungan eksternalnya

TABLE 1

Analisa SWOT pada RKU Computer.

\begin{tabular}{lll}
\hline \multicolumn{1}{c}{ SWOT } & & \multicolumn{1}{c}{ Analisa } \\
\hline Strength & $\checkmark$ & $\begin{array}{l}\text { Memiliki karyawan yang ahli dalam menangani servis banyaknya layanan service yang } \\
\text { tersedia sehingga dapat menarik berbagai customer yang mengalami masalah. }\end{array}$ \\
& $\checkmark$ & $\begin{array}{l}\text { Biaya layanan servis yang rendah dan adanya pengecekan barang sehingga customer dapat } \\
\text { memeriksa dulu kerusakan barang }\end{array}$ \\
& $\checkmark$ & Terpisah area divisi servis sehingga tidak terjadi penumpukan barang \\
\hline Weakness & $\checkmark$ & Belum adanya sistem yang mendukung proses bisnis memjadi lebih efisien, cepat da \\
& $\checkmark$ & Kurang efisien dalam proses pencatatan nota servis secara manual dan dipindahan di \\
& $\checkmark$ & Ms.excelMemungkinkan dapat terjadi penumpukan data dan kehilangan data. \\
& $\checkmark$ & $\begin{array}{l}\text { Letak RKU Computer yang strategis. } \\
\text { Opportunity }\end{array}$ \\
& $\checkmark$ & $\begin{array}{l}\text { Adanya kerjasama dengan pihak perusahaan edc sehingga memudahkan dalam } \\
\text { pengelolaan proses transaksi pembayaran }\end{array}$ \\
& $\checkmark$ & $\begin{array}{l}\text { Banyaknya pesaing Cv. Ria Kencana Ungu yang bergerak dalam bidang yang sama } \\
\text { dan memungkinkan dapat mengalami penurunan order juga servis. }\end{array}$ \\
& $\checkmark$ & Munculnya pesaing-pesaing usaha yang sama dengan RKU Computer.
\end{tabular}

\section{B. Identifikasi Masalah Enterprise}

Hasil pengamatan dan tinjauan langsung di Cv. Ria Kencana Ungu, dipaparkan beberapa permasalahan berhubungan dengan proses bisnis dan dukungan teknologi informasi sebagai berikut:

a. Proses bisnis belum terdokumentasi dengan baik serta pembagian kerja di masing-masing divisi belum berjalan dengan baik.

b. Dengan belum adanya dukungan sistem berbasis teknologi serta pemanfaatan teknologi informasi dalam mendukung fungsi bisnis.

c. Belum maksimalnya perencanaan pengembangan sistem informasi yang dapat memberikan arah dalam pengembangan sistem informasi ke depan atau lebih baik yang menunjang proses bisnis.

d. Banyak nya pesaing RKU Computer sehingga dapat mengalamai penurunan perusahaan. 


\subsection{Implementasi Zachman Framework}

Tentang perancangan architecture untuk kondisi dimasa depan, dengan menggunakan zachman framework berdasarkan kondisi yang telah di analisa. Zachman Framework terdapat dua cara untuk merancang suatu architecture yang baru didalam perusahaan. Cara pertama berdasarkan 6 (enam) pertanyaan dasar, dimana pada matriks zachman framework 6 (enam) pertanyaan dasar tersebut menjadi daftar kolom dan masing-masing pertanyaan mewakili abstraksi dari architecture tersebut, seperti pertanyaan what mewakili abstraksi data, sedangkan pertanyaan how mewakili abstraksi fungsi, lalu pertanyaan where mewakili abstraksi jaringan, pertanyaan who mewakili abstraksi orang, pertanyaan when mewakili abstraksi waktu.

\subsubsection{Perspektif Planner (Scope)}

TABLE 2

Perspektif Palner

\begin{tabular}{ll}
\hline \multicolumn{1}{c}{ Kolom } & \multicolumn{1}{c}{ Pesrspektif } \\
\hline What (Data & $\begin{array}{l}\text { Kolom ini membahas mengenai data-data atau entitas untuk mengidentifikasikan daftar entitas yang } \\
\text { menjadi hal-hal penting pada masing-masing bagian di dalam proses yang ada di Cv. Ria Kencana Ungu, } \\
\text { Uraian daftar entitas yang memiliki peran dan tanggung jawab pada entitas bisnis. pelaku bisnis yang } \\
\text { menjadi scope untuk entitas bisnis di Cv.Ria Kencana Ungu adalah :Pemilik, Wakil Direktur, Teknisi, } \\
\text { Marketing, Kasir. Customer }\end{array}$ \\
\hline How (Fungsi) & $\begin{array}{l}\text { Membahas proses-proses yang terjadi di Cv. Ria Kencana Ungu. Terdiri atas beberapa area bisnis } \\
\text { yang berkaitan dengan proses utama yang terjadi pada pelaporan servis di RKU Computer. }\end{array}$ \\
\hline Where & $\begin{array}{l}\text { Berdasarkan hasil dari wawancara perusahaan Cv. Ria Kencana Ungu merupakan perusahaan yang } \\
\text { bergerak dalam bidang penjualan dan service. RKU Komputer merupakan perusahaan perseroan } \\
\text { komanditer (Cv) yang didirikan dipalembang. Berlokasi Jalan Jenderal Ahmad Yani No.24J, Kecamatan } \\
\text { Seberang Ulu I, Kota Palembang. Sumatera selatan. }\end{array}$ \\
\hline Who (Orang) & $\begin{array}{l}\text { Pada kolom who ini berisikan daftar unit tiap-diap divisi yang berperan dalam Cv. Ria Kencana } \\
\text { Ungu. Setiap karyawan diberikan tugas dan tanggung jawab sesuai bagian pekerjaan nya di RKU. Untuk } \\
\text { dapat lebih mudah dimengerti berikut penjelasan tugas dan tanggung jawab di RKU Komputer }\end{array}$ \\
\hline Khen (Waktu) & $\begin{array}{l}\text { Kolom when ini penjelasan mengenai siklus waktu dan menggambarkan kegiatan atau kejadian } \\
\text { peristiwa yang terjadi terkait dengan uraian kegiatan proses yang berlangsung secara keseluruhan di Cv. } \\
\text { Ria Kencana Ungu }\end{array}$ \\
\hline Why (Motivasi) & $\begin{array}{l}\text { Pada kolom why menjelaskan tentang visi misi serta tujuan dari Cv.Ria Kencana Ungu } \\
\end{array}$
\end{tabular}

\subsubsection{Perspektif Owner (Bussines Model)}

Baris kedua dari zachman framework mengenai konseptual bussines model menurut perspektif pemilik (Owner). Pada architecture ini mendefinisikan baris kedua yang dijelaskan berbagai macam aturan dan prosedur standar dari masing-masing proses bisnis yang nantinya diharapkan dapat berjalan baik, Serta menjelaskan proses-proses bisnis apa saja yang sedang dirancang. Untuk menunjangnya proses bisnis yang akan berjalan, dan juga akan menjelaskan siklus waktu tentang jalannya proses bisnis ini. Untuk lebih jelasnya akan dijelaskan perkolomnya dari zachman framework.

\section{A. Kolom What (Data)}

Use case diagram untuk menggambarkan kegiatan interaksi yang saling berkaitan antara sistem dan actor. Adapun penjelasan deskripsi actor secara rinci dijelaskan adalan sebahgai berikut. 


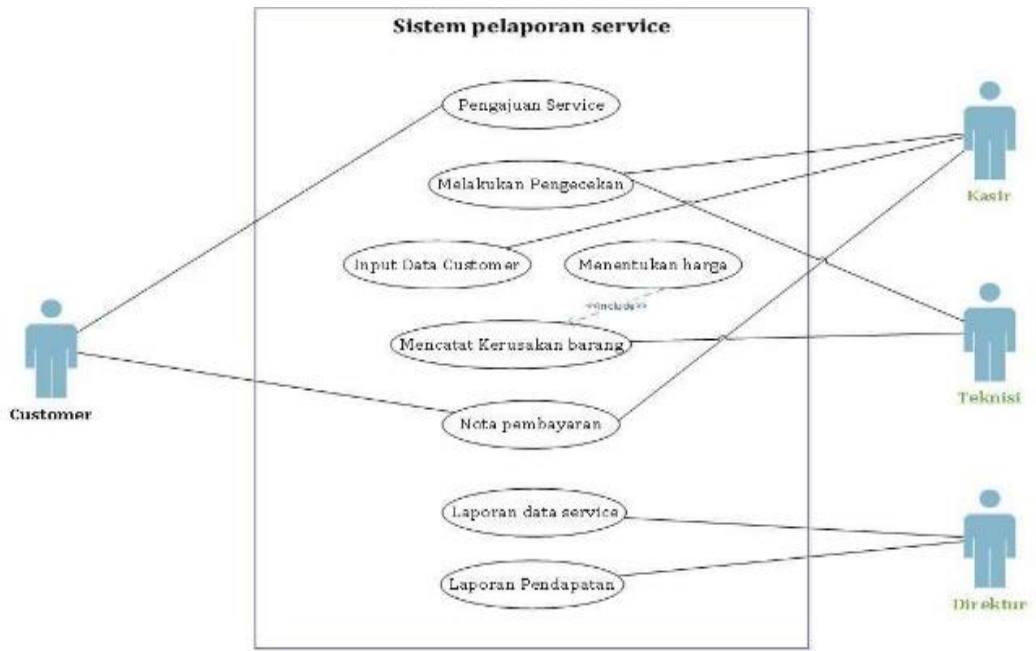

Gambar 1. Use Case Pelaporan Service RK

B. Kolom How (Fungsi)

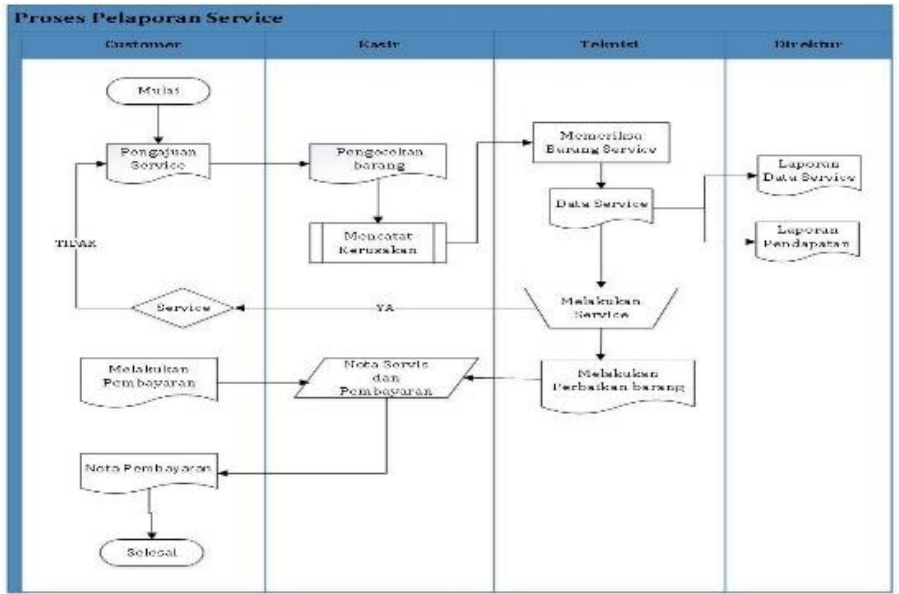

Gambar. 2 Flowmap Proses Laporan Kerusakan

C. Kolom Where (Jaringan)

Saat ini kondisi pada Cv. Ria Kencana Ungu untuk sistem yang masih berjalan secara manual dengan belum adanya sistem untuk membantu jalannya proses bisnis untuk pencatatan sendiri ditiap-tiap bagian masih melakukan bantuan microsoft excel. Oleh karena itu Cv. Ria Kencana Ungu belum mempunyai jaringan yang dapat menghubungkan data keberbagai tiap-tiap divisi di Cv. Ria Kencana Ungu.

\section{Kolom Who (Orang)}

Pada kolom ini tentang alur proses kerja di Cv. Ria Kencana Ungu dimulai ketika pelanggan datang ke Cv. Ria Kencana Ungu untuk mencari produk dan dilayani oleh bagian marketing atau juga untuk mengajukan service dan diterima pada bagian kasir dilakukan pengecekan terhadabarang customer yang akan di service dan di catat lalu bagian teknisi datang ke pos pelayanan service dan memeriksa barang service yang telah di data bagian kasir, Teknisi mencatat dipapan kerusakan dibagian divisi service setelah di periksa bagian servis kasir menentukan harga dari pencatatan yang diterima oleh bagian teknisi, Bagian kasir membuat nota servis dan pembayaran. Wakil direktur merekap laporan pendapatan selama proses tranksasi yang berjalan di Cv. Ria Kencana Ungu dan membuat laporan untuk diberikan kepada direktur RKU Computer selakupemilik dari Cv. Ria Kencana Ungu. 


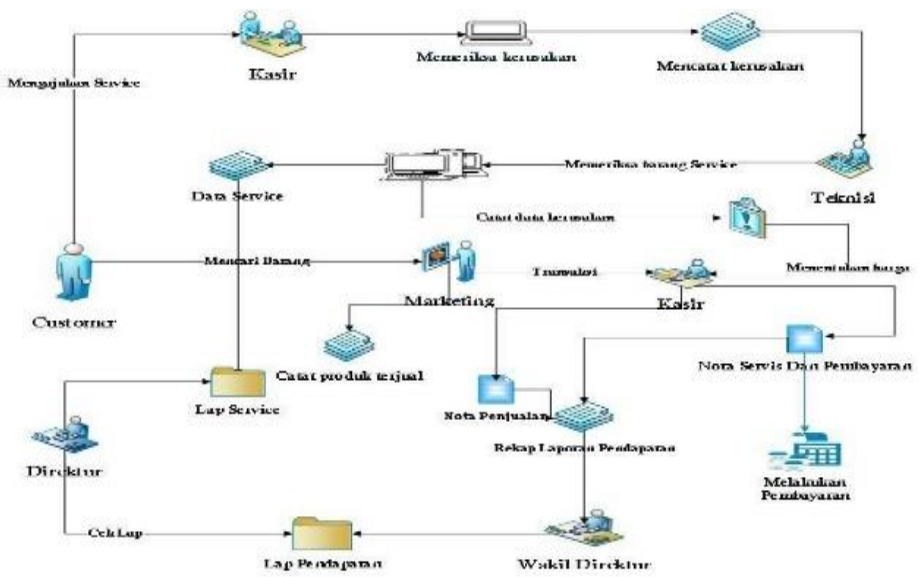

E. Kolom When (Waktu)

Gambar 3 Workflow Organisasi Saat

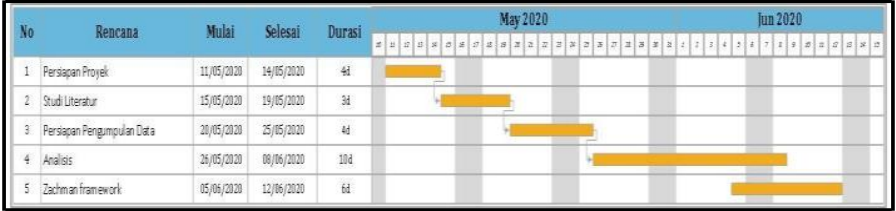

Gambar 4. Pembuatan EAP

\section{F. Kolom Why (Motivasi)}

Karena keterbutuhan bisnis yang sudah cukup besar Cv. Ria Kencana Ungu akhirnya mengadakan Enterprise Architechture Planning (EAP) dalam model bisnisnya dikarenakan ingin membuat sistem Cv. Ria Kencana Ungu lebih terorganisir secara rapi agar dalam pencatatan dan laporan semua data yang ada dapat terdata dan tersusun secara rapi dalam sistem dan dapat memudahkan karyawan dalam mengakses data yang terdapat dalam proses bisnis RKU Computer seperti data servis, barang masuk dan data lainya. Tahapan ini sebagai landasan untuk tahapan pengerjaan berikutnya tujuan dari pemodelan bisnis ini untuk menyediakan dasar pengetahuan menyeluruh yang dapat digunakan untuk mendefinisikan architecture yang dibutuhkan untuk mendukung aktifitas bisnis menentukan jalur yang jelas untuk berpindah dari posisi saat ini ke posisi yang diinginkan di masa depan, Diharapkan dengan adanya sistem ingin membuat proses bisnis berjalan dengan optimal, memaksimalkan kinerja pada tiaptiap bagian di RKU Computer.

\subsubsection{Perspektif Designer (System Model)}

A. Kolom What (Data)

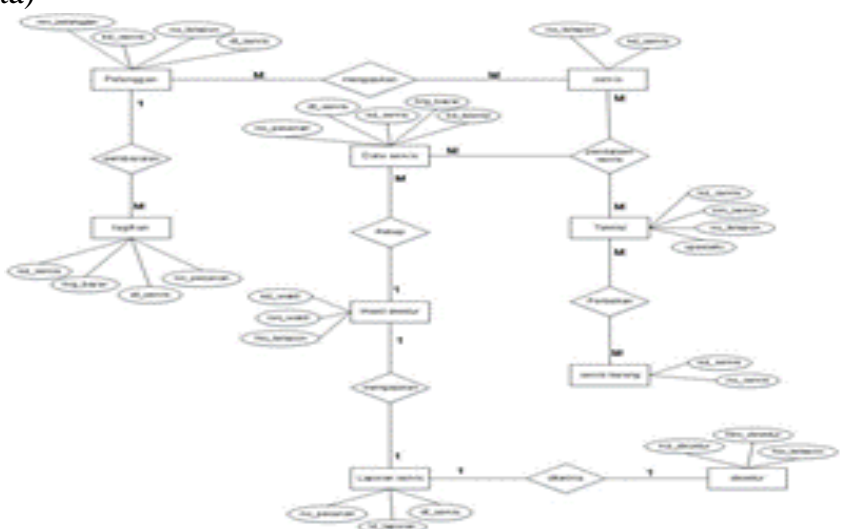

Gambar 5. Entity Relationship Diagram 


\section{B. Kolom How (Fungsi)}

Kolom how langkah pemodelan dibuat menggunakan activity diagram yang menggambarkan alur berjalannya proses bisnis penjualan, service dan laporan pada Cv. Ria Kencana Ungu. Proses yang berjalan pada 6 objek swimlane yang merupakan entitas data. Pada activity diagram Entitas tersebut yaitu customer, teknisi, kasir, direktur (pemilik), marketing, wakil direktur.

\section{Kolom Where (Jaringan)}

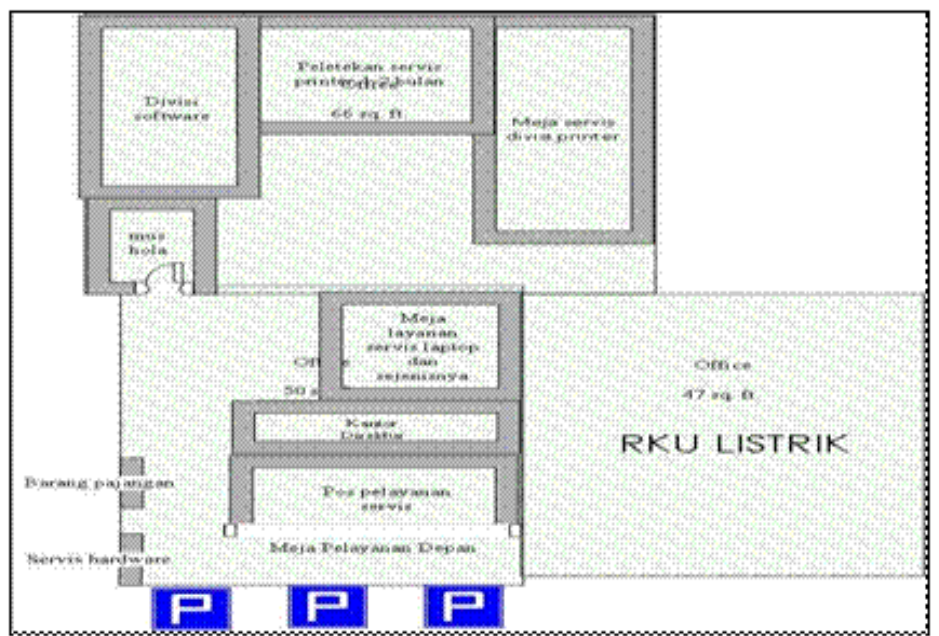

Gambar 6. Struktur mapping

\section{Kolom Who (Orang)}

Rancangan Input Form login Menu ini adalah tampilan login untuk beberapa pengguna sistem RKU Computer yaitu Direktur, Wakil Direktur, Kasir atau Marketing dan Teknisi. Tampilan menu semua aktor tersebut sama, yang menentukan masuk kedalam sistem informasi suatu sistem tergantung pada kode login yang dimiliki masing-masing aktor. Rancangan Halaman Utama Tampil rancangan halaman utama dalam design interface aplikasi tampilan utama ini sebelum login pada menu masing-masing pengguna.

\section{E. Kolom When (Waktu)}

Kolom when ini penjelasan mengenai siklus waktu tentang jadwal kegiatan pembuatan aplikasi pada $\mathrm{Cv}$. Ria Kencana Ungu

\section{F. Kolom Why (Motivasi)}

Membahas batasan-batasan atau juga aturan yang nantinya diterapkan dalam proses perancangan sistem model, desain application enterprise architecture planning (EAP).

\subsubsection{Perspektif Builder (Technology Model)}

\section{A. Kolom What (Data)}

Tentang pembuatan desain tabel pada tabel ini berfungsi untuk menyimpan data yang terdiri dari field-field yaitu nm_pelanggan, kd_servis,, dt_sevis. kd_teknisi, nm_teknisi, no_telepon, spesialis kd_wakil, nm_wakil,. no_pesanan,, hrg_bayar, dt_servis. 
B. Kolom How (Fungsi)

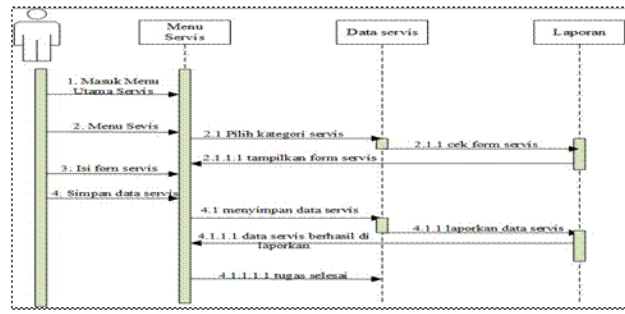

Gambar 7. Diagram Squence

C. Kolom Where (Jaringan)

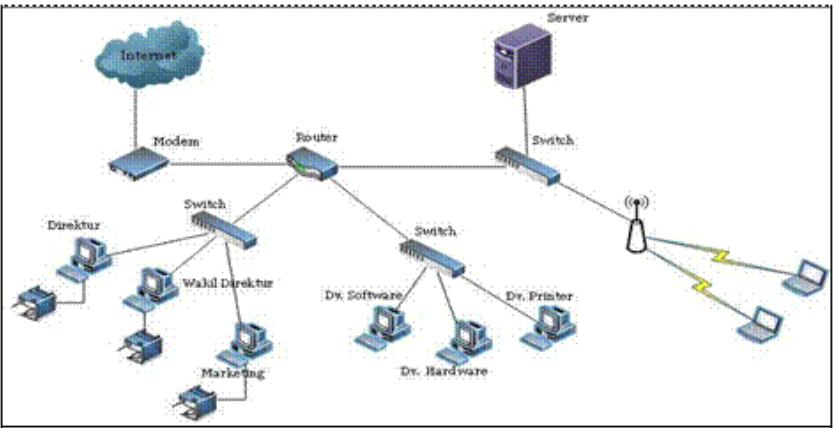

Gambar 8. Struktur Jaringan Usulan

\section{Kolom Who (Orang)}

Pembuatan design Interface rancangan Tambah Data Servis dalam menu ini, bagian marketing yang bertugas dalam memasukkan seluruh data servis yang terjadi di RKU Computer dengan hasil output berupa laporan data servis yang akan masuk kedalam server yang akan masuk kedalam menu laporan yang dimiliki oleh Direktur dan Wakil Direktur

\section{E. Kolom When (Waktu)}

Pemaparan tahapan penjadwalan perancangan aplikasi pada sistem Cv. Ria Kencana Ungukedepannya teknologi atau platform dalam merespon kegiatan di dalam perusahaan nantinya terdiri dari pembuatan database, interface application dalam mendukung proses perancangan aplikasi agar dapat lebih efektif.

\section{F. Kolom Why (Motivasi)}

Spesifikasi fisik aturan yang diterapkan dalam proses perancangan aplikasi. Bertujuan sebagai pedoman untuk perusahaan dimasa depan dalam mengembangkan technologi information agar sistem tersusun dengan baik dan terintegrasi tiap-tiap antar bagian

\section{Kesimpulan}

Berdasarkan yang telah dipaparkan dari pembahasan hasil penelitian Perancangan Enterprise Architecture Planning Dengan Zachman Framework (Studi Kasus : Cv.Ria Kencana Ungu), maka dapat ditarik beberapa kesimpulan, antara lain :

1. Dari penelitian ini hasil yang dicapai dalam pelaksanaan enterprise architecture planning menghasilkan sebuah cetak biru yang dapat dijadikan sebagai pedoman dalam mengembangkan sistem informasi dimasa yang akan datang dan mengurangi masalah-masalah perusahaan dalam 
pengembangan sistem informasi dan teknologi. Cetak biru yang dihasilkan melalui metode enterprise architecture planning dan kerangka zachman framework dapat menggambarkan dengan merancang architecture di Cv.Ria Kencana Ungu terbukti menjadi hal yang sangat penting bagi sebuah enterprise.

2. Enterprise architecture planning dapat diterapkan sebagai upaya dalam menyelaraskan IT didalam proses bisnis perusahaan. berhubungan dengan bagaimana kebutuhan teknologi informasi dimasa yang akan datang harus disesuaikan dengan model proses bisnis pada Cv. Ria Kencana Ungu. Dengan di terapkan kandidat aplikasi yang di usulkan dapat memperbaiki sistem informasi berdasarkan proses bisnis yang sedang berjalan saat ini sehingga terciptanya suatu konsep kebutuhan teknologi informasi yang mendukung kebutuhan bisnis yang bisa menjadi acuan dalam investasi teknologi jangka panjang di Cv. Ria Kencana Ungu dengan mempertimbangkan kepentingan dan kebutuhan perusahaan.

\section{Daftar Pustaka}

[1] Bachri, B. S. (1986) 'Bachri, B. S., Pendidikan, T., \& Pendidikan, F. I. (1986). Meyakinkan Validitas Data Melalui Triangulasi Pada Penelitian Kualitatif.'

[2] Lapalme, J. et al. (2016) 'Exploring the future of enterprise architecture: A Zachman perspective',Computers in Industry. Elsevier, 79, pp. 103-113.

[3] Rangkuti, F. (2006) Analisis SWOT Teknik Membedah Kasus Bisnis. Gramedia Pustaka Utama.

[4] Sulaiman, R. (2016) 'Perancangan Strategis Perencanaan Sistem Informasi Menggunakan

[5] Surendro, K. (2007) 'Pemanfaatan Enterprise Architecture Planning untuk Perencanaan Strategis Sistem Informasi’, Jurnal Informatika, 8(1), pp. 1-9. 